Research Article

\title{
The Study for Saving Energy and Optimization of LED Street Light Heat Sink Design
}

\author{
Chi-Chang Hsieh ${ }^{1}$ and Yan-Huei $\mathbf{L i}^{2}$ \\ ${ }^{1}$ Department of Mechanical and Automation Engineering, National Kaohsiung First University of Science and Technology, \\ Kaohsiung 82445, Taiwan \\ ${ }^{2}$ Institute of Engineering Science and Technology, National Kaohsiung First University of Science and Technology, \\ Kaohsiung 82445, Taiwan
}

Correspondence should be addressed to Chi-Chang Hsieh; cchsieh@nkfust.edu.tw

Received 25 September 2014; Accepted 15 March 2015

Academic Editor: Ying Liu

Copyright (C) 2015 C.-C. Hsieh and Y.-H. Li. This is an open access article distributed under the Creative Commons Attribution License, which permits unrestricted use, distribution, and reproduction in any medium, provided the original work is properly cited.

\begin{abstract}
LED lamps are characterized by high energy efficiency, high luminance, and long lifespans. However, the heat radiation problem caused by the extra high power shortens the lifespan and reduces the luminous efficiency of such lamps. This study introduced the development of a novel cooling fin structure for LED lamps and compared its performance with those of commercially available products. The objective of the design was to reduce the maximum temperature and temperature difference on the fin, the amount of aluminum required for fin manufacturing, and $\mathrm{CO}_{2}$ emissions to save energy. The study employed the Taguchi method for experiment planning and used gray relational analysis and principal component analysis to determine the optimal parameter combination for cooling fins. The results showed that the maximum temperature on the fin surface dropped by $2.62^{\circ} \mathrm{C}$ in environments without forced convection, which indicated improved lighting efficiency. Furthermore, the amount of aluminum used per unit volume for fins was reduced by $15 \%$, which effectively reduced $\mathrm{CO}_{2}$ emissions during the manufacturing process.
\end{abstract}

\section{Introduction}

Light-emitting diodes (LEDs) have been widely used in recent years. Because LED-based lighting sources have the advantages of high luminous efficacy, a long lifespan and do not contain mercury, they have attracted people's attention. Before related regulations were implemented, many manufacturers developed LED-based street lights that received an encouraging response from the emerging market; however, numerous problems have been identified in these lights and remain to be solved, such as heat dissipation problems caused by high power, illumination-related legislation, mechanisms and optical design for light sources, the new requirement for power saving, and high prices. Therefore, the research and development of a low-cost and high-efficiency heat dissipation system can expedite the development of the market for LED illumination, promote LED applications, and achieve the goal of reducing energy consumption and carbon emission.
As shown in Figure 1, the junction temperature of the LED light analyzed in this study was inversely proportional to light output efficiency. As the junction temperature increased from room temperature to $100^{\circ} \mathrm{C}$, the light output gradually decreased, resulting in light-induced degradation. Regarding lifespan, when the junction temperature reached approximately $70^{\circ} \mathrm{C}$, the lifespan of the LED street light degraded by $75 \%$. Therefore, to enable the light source of an LED street light to achieve optimal performance, the design of fin heat sinks for LED street lights is vital for the improvement of light output efficiency and lifespan extension.

The heat dissipation problem is one of the problems at the LED design. In this study we proposed a design method to replace fins for LED street lights. To be compared between the commercial fins and novel fins. The primary material comprising fin heat sinks for street lights is aluminum alloy, the production process of which typically emits a substantial amount of $\mathrm{CO}_{2}$. According to the statistics, producing $1 \mathrm{~kg}$ of aluminum yields $10.233 \mathrm{~kg}$ of $\mathrm{CO}_{2}$. Therefore, the effective 


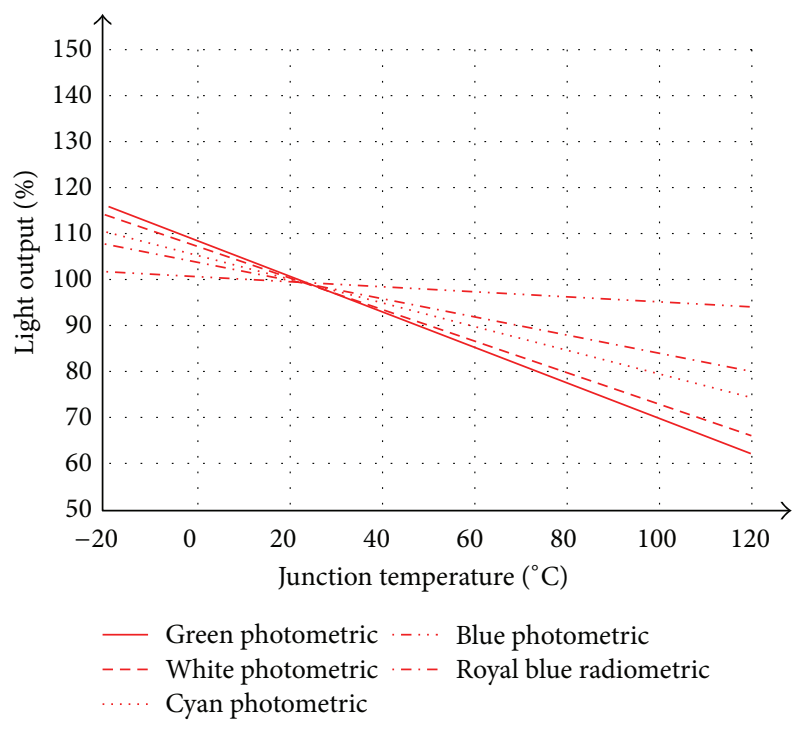

FIGURE 1: Relationship between the LED junction temperature and light output.

reduction of aluminum in fin heat sinks can reduce the emission of $\mathrm{CO}_{2}$ and the weight of the fin heat sinks.

\section{Literature Review}

Numerous parameters may influence the heat dissipation effect of fin heat sinks. Kim et al. [1] compared plate-fin and pin-fin heat sinks and determined that the heat dissipation performance of plate-fin heat sinks was superior to that of pin-fin heat sinks when wind velocity was high and the fins were short. Conversely, with low wind velocity and long fins, the pin-fin heat sinks exhibited superior heat dissipation performance compared with that of the platefin heat sinks. Sahiti et al. [2] compared the performance of airfoil-shaped streamline fins developed by the National Advisory Committee for Aeronautics and drop-shaped fins with that of elliptic, circular, and square pin fins under various conditions. And Chang and Lees [3] show a novel compound heat transfer enhancement (HTE) measure. It combines deepened scales and pin-fin array to strengthen cooling. Moreover, because of the trend of product weight reduction, numerous studies have investigated designs for the weight reduction of fin heat sinks such as hollow or perforated fin heat sinks. Tony Tan et al. [4] present hollow geometry introduced inside the rectangular fins and used three kinds of hollow geometries (circular, rectangular, and trapezoidal). The results show that the "hollowed" fins have better heat dissipation efficiency compared to the solid fins. And Elshafei [5] compared solid and hollow circular pin fins and investigated the influence of the thickness of hollow pin fins on the temperature difference among the fins. The result revealed that the hollow pin fins exhibited a comparatively small temperature difference and light weight, compared with that of the solid pin fins. Additionally, as the thickness of the hollow pin fins increased, the temperature difference decreased. In recent years, the design optimization of quality characteristics has become required in the field of engineering. Sahin et al. $[6,7]$ applied the Taguchi method to design perforated rectangular and circular fin heat sinks, which achieved optimal heat dissipation performance. They reported that the heat dissipation efficiency was influenced the most by wind velocity, followed by the fin height and fin spacing.

\section{Experimental Design and Operation}

A lighting test was first conducted on the sample to measure the temperature distribution among the fins and the highest temperature of the fins. Subsequently, a computer-aided simulation was conducted by using ANSYS software; the simulation result was compared with the actual measurement result to confirm that the errors in the simulation result were within the tolerance range. Therefore, the new fin heat sink was further simulated. The LED light source used as a reference sample comprised 50 Cree XLamp XR-E LEDs (2.5 W/diode). The material of the fin heat sink was A6061 aluminum alloy; the heat transfer coefficient was $0.154 \times$ $10^{-3} \mathrm{~W} / \mathrm{mm}^{\circ} \mathrm{C}$. Because the fin heat sink was symmetrical, only half of the heat sink was used in the simulation to reduce the calculation time. The reference sample and simulation result were compared. The highest and lowest temperature of the base of the sample heat sink were $47.8^{\circ} \mathrm{C}$ and $36.8^{\circ} \mathrm{C}$, respectively, whereas those of the heat sink base in the simulation were $45.7^{\circ} \mathrm{C}$ and $36.7^{\circ} \mathrm{C}$, respectively. The errors between the two results regarding the highest and lowest temperature were $4.4 \%$ and $0.3 \%$, which were within the tolerance range of $5 \%$. In addition, based on the room temperature at $24^{\circ} \mathrm{C}$ and outdoor temperature at $22^{\circ} \mathrm{C}$, the heat transfer coefficient $(\mathrm{h})$ for the indoor environment was $10 \times 10^{-6} \mathrm{~W} / \mathrm{mm}^{\circ} \mathrm{C}$ and that for the outdoor environment was $25 \times 10^{-6} \mathrm{~W} / \mathrm{mm}^{\circ} \mathrm{C}$. In addition, the total surface area and the material weight of the reference sample were $138000 \mathrm{~mm}^{2}$ and $921.3 \mathrm{~g}$, respectively. The amount of $\mathrm{CO}_{2}$ generated from the production of fins was $9.4 \mathrm{~kg}$.

\section{Design of a Novel Fin Heat Sink for Street Lights}

4.1. Type Area Simulation Parameters for the Model of Street Light. The power consumption of the reference sample street light was $125 \mathrm{~W}$, which was low compared with other types of street lights. To expand the application range of the newly designed fin heat sink, the power consumption was increased to $180 \mathrm{~W}$ in the design of the new fin heat sink. Specifically, various wattages were applied to the reference sample for the simulation, and the results were compared. When the power consumption of the reference sample was $125 \mathrm{~W}$, the highest temperature of the fins was $45.6^{\circ} \mathrm{C}$. When the power consumption was increased to $180 \mathrm{~W}$, the highest temperature increased to $55.1^{\circ} \mathrm{C}$ (increasing by $9.5^{\circ} \mathrm{C}$ )

4.2. Optimization Analysis of the New Fin Heat Sink. In this section, the influence of numerous parameters on the heat dissipation performance of the fin heat sink is examined. 
TABLE 1: Parameter and parameter levels of the novel fin heat sink.

\begin{tabular}{|c|c|c|c|c|}
\hline \multirow{2}{*}{ Control parameters } & \multicolumn{4}{|c|}{ Parameter levels } \\
\hline & Level 1 & Level 2 & Level 3 & Level 4 \\
\hline Fin type & Rectangular plate & Trapezoidal plate & Square pin & Circular pin \\
\hline Fin spacing $(\mathrm{mm})$ & 10 & 14 & - & - \\
\hline Fin arrangement & Parallel & Staggered & - & - \\
\hline Fin height (mm) & 40 & 50 & - & - \\
\hline Thickness of heat sink base (mm) & 5 & 10 & - & - \\
\hline
\end{tabular}

TABLE 2: Performance comparison between the new hollow fin heat sink and reference sample.

\begin{tabular}{lccc}
\hline Performance & \multicolumn{2}{c}{ Fin heat sinks } \\
& Reference sample & Novel hollow fin heat sink & Gains \\
\hline Highest temperature in an outdoor environment $\left({ }^{\circ} \mathrm{C}\right)$ & 40.1 & 37.5 & Decreased by $6.5 \%$ \\
Total surface area $\left(\mathrm{mm}^{2}\right)$ & 138000 & 313270 & Increased by $127 \%$ \\
Material weight $(\mathrm{g})$ & 921.3 & 782.4 & Decreased by $15 \%$ \\
The amount of $\mathrm{CO}_{2}$ emission $(\mathrm{kg})$ & 9.4 & 8 & Decreased by $15 \%$ \\
\hline
\end{tabular}

Adequate parameter levels were determined for analysis. An excessive number of design parameters for fin heat sinks could have caused the experiment to be complicated and time consuming. Therefore, in this study, the fin length and thickness were fixed and integrated with fin shape to produce a newly designed parameter. In the experiment, five parameters were used as control factors: fin type, fin spacing, fin arrangement, fin height, and the thickness of the heat sink base. The parameters and parameter levels are listed in Table 1. And we fixed the fin length and thickness. This is because we want to keep the fins area and volume of distribution. This is related to two objectives of this paper, to reduce material and production costs. The experiment for the design optimization of the new fin heat sink involved a total of five parameters. Except for the fin type, which was a four-level parameter, the other parameters comprised only two levels. In addition, an interaction effect existed among the parameters. Therefore, $L_{32}$ and $L_{9}$ were used as the inner and outer orthogonal arrays, respectively, for the optimization experiment. After the optimization analysis, the new fin heat sink produced based on the optimal combination of parameter levels was compared with the reference sample. According to the comparison result, the highest temperature of the new fin heat sink was $1.4^{\circ} \mathrm{C}$ lower than that of the reference sample. However, the production of new fins required an additional $770.3 \mathrm{~g}$ of aluminum alloy, resulting in an additional $7.9 \mathrm{~kg}$ of emitted $\mathrm{CO}_{2}$.

4.3. Optimization Analysis of the Novel Hollow Heat Sink. To optimize the efficiency of the novel fin heat sink and reduce the amount of aluminum used, optimization was conducted for a second time to improve the structure of the first novel fin heat sink developed. Specifically, the structures of the four types of fins applied to the first fin heat sink were modified, as shown in Figure 2. By adopting a hollow structure, the amount of materials used to produce a single fin decreased, and the exposure of the fin to the air increased. Additionally, the thickness of the heat sink

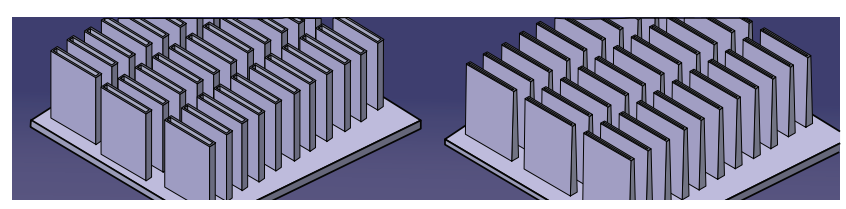

Rectangular plate

Trapezoidal plate

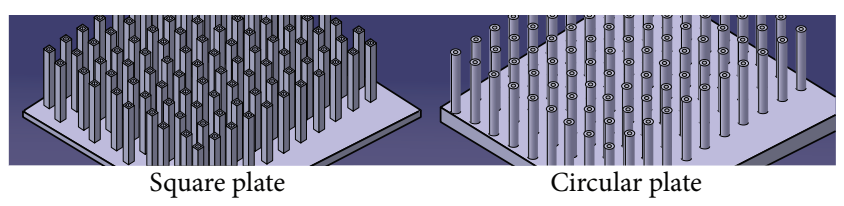

Figure 2: Types of hollow fin heat sinks.

base was adjusted from $5 \mathrm{~mm}$ to $3 \mathrm{~mm}$ and from $10 \mathrm{~mm}$ to $5 \mathrm{~mm}$. By performing optimization analysis for a second time, a hollow fin heat sink was produced based on the optimal combination of parameter levels and was compared with the reference sample; the comparison result is summarized in Table 2. The highest temperature of the new hollow fin heat sink was $2.6^{\circ} \mathrm{C}$ lower than that of the reference sample. The amount of aluminum material used for producing the hollow fin heat sink was $138.9 \mathrm{~g}$ less than that used for the reference sample, resulting in a reduction of $1.4 \mathrm{~kg}$ in $\mathrm{CO}_{2}$ emission during the production of fins.

4.4. Examination of Hollow Fin Thickness. The new hollow fin heat sink successfully achieved cost reduction and the improvement of heat dissipation efficiency; the achievement can be mainly attributed to the hollow structure of the fins. Because of the hollow structure, the contact area of the fins with the air increased, and the amount of material used to produce the fins decreased, leading to a reduction in cost and fin weight. The optimization analysis used in this study revealed that the heat dissipation performance of the hollow fin heat sink was superior to that of the solid fin heat sink. This 


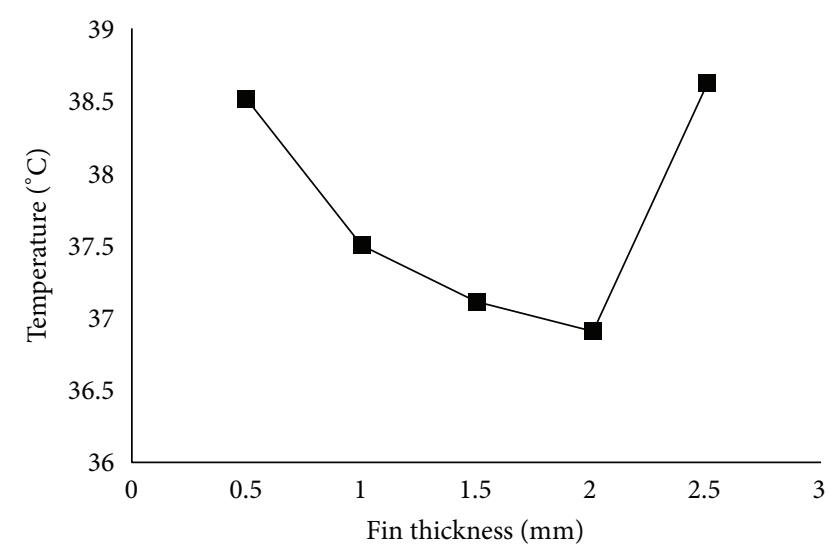

FIgURE 3: Relationship between the thickness of hollow fins and the highest temperature of the fins.

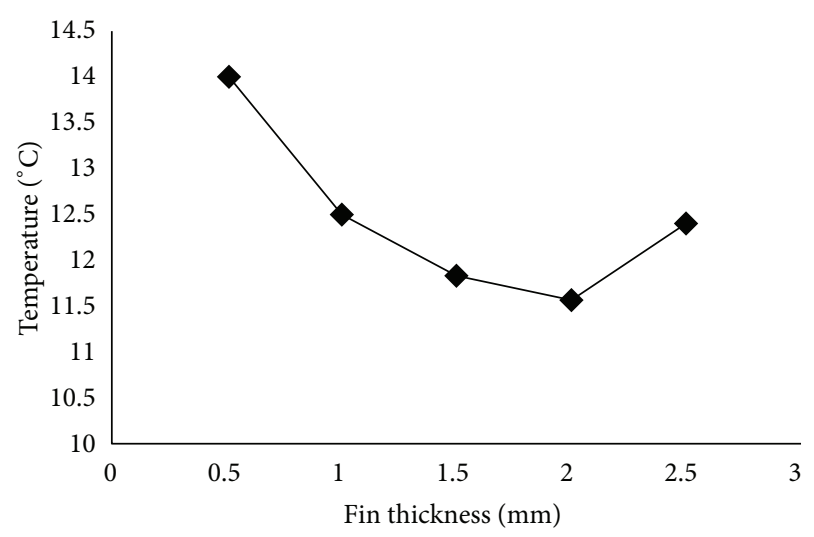

FIgURE 4: Relationship between the thickness of hollow fins and the temperature difference among fins.

section provides a discussion on the thickness of the hollow fins.

This study targeted a rectangular plate-fin heat sink. The width of the fins was set at $5 \mathrm{~mm}$; therefore, the thickness of the hollow fins was set at $0.5 \mathrm{~mm}, 1 \mathrm{~mm}, 1.5 \mathrm{~mm}, 2 \mathrm{~mm}$, and $2.5 \mathrm{~mm}$ (i.e., the thickness of the solid fins). Heat-flow analysis was conducted in an outdoor environment; the influences of the various levels of fin thickness on quality characteristics were compared. Thus, the optimal thickness of the hollow fins was obtained. According to Figures 3 and 4 , the highest temperature and the temperature difference exhibited by the hollow fins were both lower than that exhibited by the solid fins. The lowest values were achieved when the fin thickness was $2 \mathrm{~mm}$. Regarding the temperature difference, when the fin thickness was greater than $1 \mathrm{~mm}$, the total volume of the hollow fins exceeded that of the reference sample. Therefore, the analysis of hollow fin thickness verified that optimal performance can be achieved when the fin thickness is $1 \mathrm{~mm}$. In other words, the hollow fin heat sink possessed the advantages of satisfactory heat dissipation performance and low production cost.

\section{Conclusion}

The purpose of this study was to develop a robust design for fin heat sinks based on existing fin heat sinks used for LED street lights. By reducing the highest temperature of the fins, the temperature difference among the fins, the use of aluminum materials, and the emission of $\mathrm{CO}_{2}$, the goal of reducing carbon emission and energy can be achieved. By conducting optimization analysis twice, the following conclusions were derived.

(a) The significant control factors that influenced multiple quality characteristics of the fin heat sinks were fin type, the thickness of the heat sink base, and fin spacing, ordered in a descending sequence from high to low degrees of influence. The total contribution rate was $92.45 \%$. Furthermore, fin type had a contribution rate of $57.87 \%$ and, therefore, was the most influential control factor. The optimal parameter for novel fin heat sink: hollow rectangular plate, thickness of the heat sink base is $5 \mathrm{~mm}$, fin arrangement is staggered, fin height is $50 \mathrm{~mm}$, and fin spacing is $10 \mathrm{~mm}$.

(b) The verification experiment revealed that the predicted values and the experimental values obtained by optimizing the grey relational grade twice were similar. All the experimental values of the grey relational grade were within the $95 \%$ confidence interval, demonstrating that the experiment was successful and reliable.

(c) The novel hollow fin heat sink produced after performing optimization analysis twice was compared with the reference sample in an outdoor environment. According to the comparison result, the highest temperature, the amount of aluminum usage, and the amount of $\mathrm{CO}_{2}$ emission in the production of the new hollow fin heat sink were $2.62^{\circ} \mathrm{C}, 138.9 \mathrm{~g}$, and $1.4 \mathrm{~kg}$, respectively, all of which were lower than those of the reference sample. Additionally, the difficulty of producing the new fin heat sink decreased because of its simple appearance.

(d) When the novel hollow fin heat sink was applied to a $180 \mathrm{~W}$ street light, the highest temperature of the fins was $46.8^{\circ} \mathrm{C}$, which was lower than the highest temperature exhibited by the reference sample applied to a $125 \mathrm{~W}$ street light $\left(48.3^{\circ} \mathrm{C}\right)$. Therefore, the novel hollow fin heat sink designed in this study can be applied to an LED light source with high wattage.

\section{Conflict of Interests}

The authors declare that there is no conflict of interests regarding the publication of this paper.

\section{Acknowledgment}

This research was partly sponsored by the Ministry of Science and Technology under Contract 103-2221-E-327-039-. 


\section{References}

[1] D. K. Kim, S. J. Kim, and J. K. Bae, "Comparison of thermal performances of plate-fin and pin-fin heat sinks subject to an impinging flow," International Journal of Heat and Mass Transfer, vol. 52, no. 15-16, pp. 3510-3517, 2009.

[2] N. Sahiti, A. Lemouedda, D. Stojkovic, F. Durst, and E. Franz, "Performance comparison of pin fin in-duct flow arrays with various pin cross-sections," Applied Thermal Engineering, vol. 26, no. 11-12, pp. 1176-1192, 2006.

[3] S. W. Chang and A. W. Lees, "Endwall heat transfer and pressure drop in scale-roughened pin-fin channels," International Journal of Thermal Sciences, vol. 49, no. 4, pp. 702-713, 2010.

[4] H. J. Tony Tan, M. Z. Abdullah, and M. Abdul Mujeebu, "Effects of geometry and number of hollow on the performance of rectangular fins in microchannel heat sinks," Isi Bilimi Ve Teknigi Dergisi/Journal of Thermal Science and Technology, vol. 33, no. 1, pp. 1-9, 2013.

[5] E. A. M. Elshafei, "Natural convection heat transfer from a heat sink with hollow/perforated circular pin fins," Energy, vol. 35, no. 7, pp. 2870-2877, 2010.

[6] B. Sahin and A. Demir, "Performance analysis of a heat exchanger having perforated square fins," Applied Thermal Engineering, vol. 28, no. 5-6, pp. 621-632, 2008.

[7] B. Sahin and A. Demir, "Thermal performance analysis and optimum design parameters of heat exchanger having perforated pin fins," Energy Conversion and Management, vol. 49, no. 6, pp. 1684-1695, 2008. 

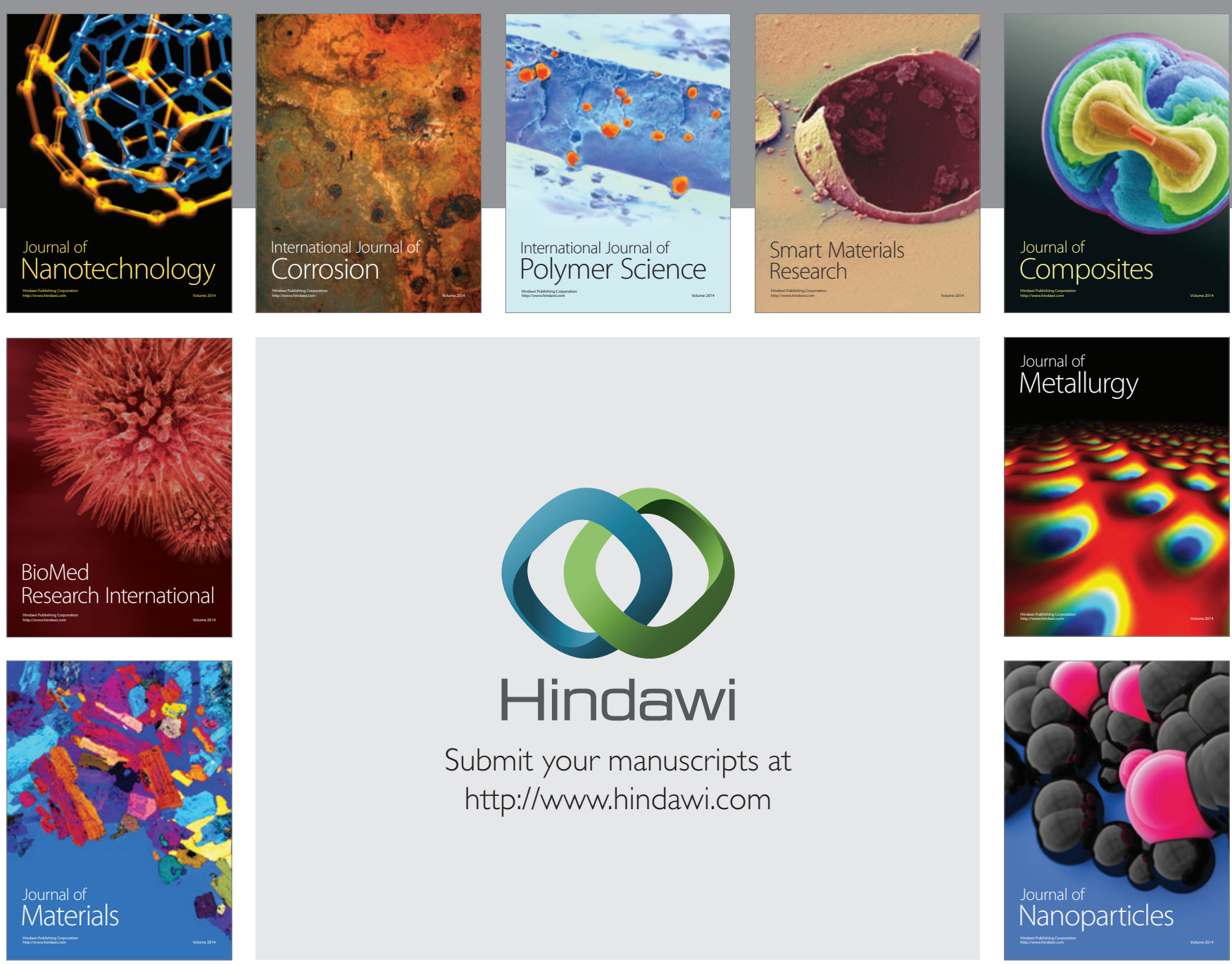

Submit your manuscripts at http://www.hindawi.com
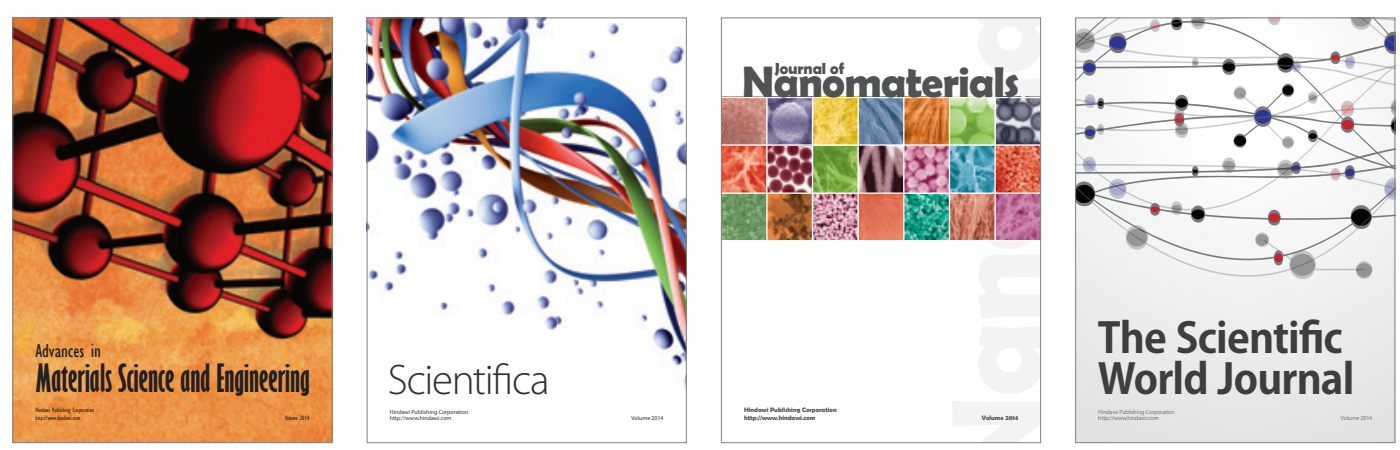

\section{The Scientific World Journal}
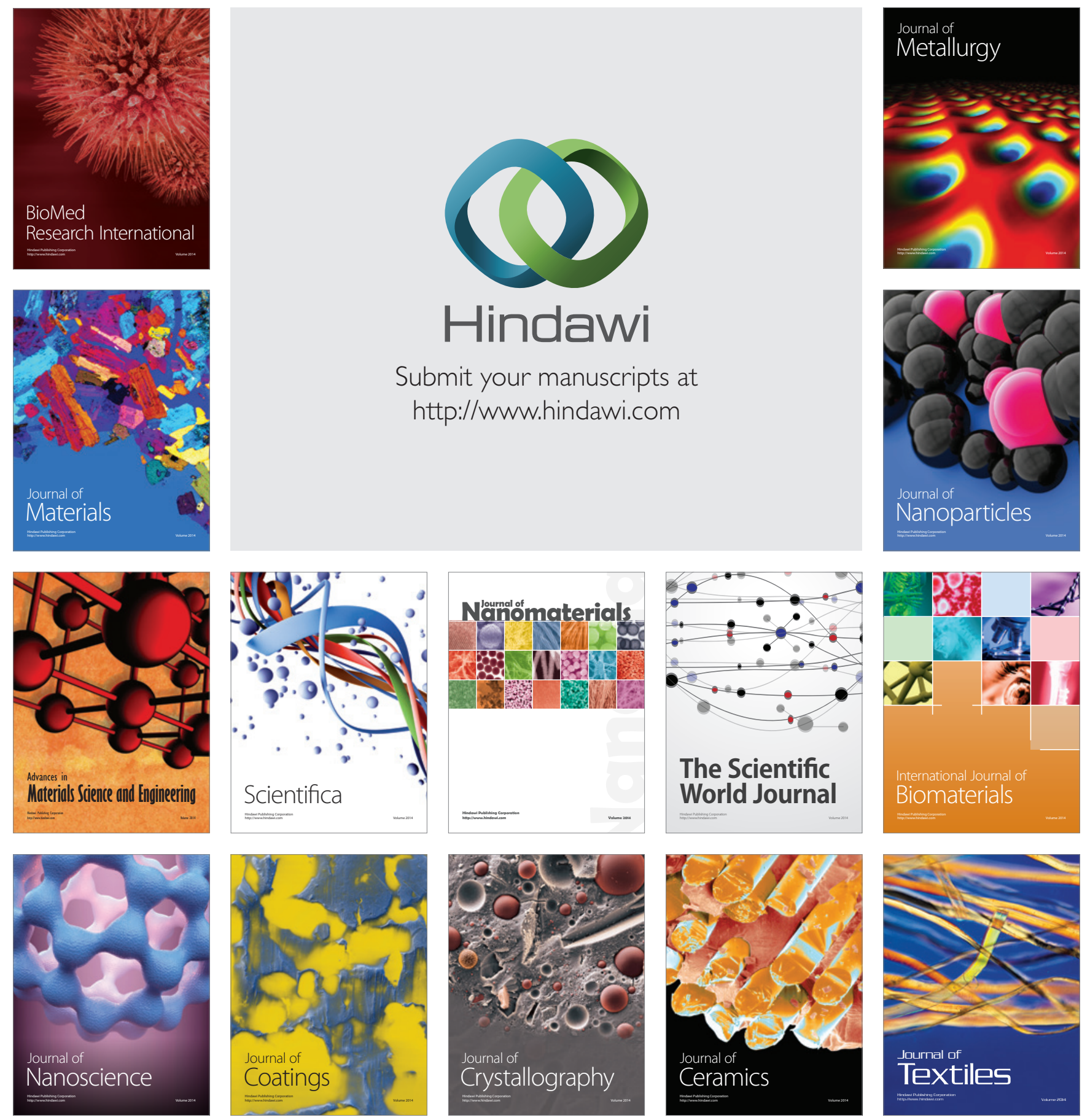